\title{
PENERAPAN FUZZY MULTIPLE ATTRIBUTE DECISION MAKING DALAM PEMILIHAN TEMPAT INDEKOS
}

\author{
I Nyoman Dicky Wijaya ${ }^{1 \S}$, G. K. Gandhiadi ${ }^{2}$, Luh Putu Ida Harini ${ }^{3}$ \\ ${ }^{1}$ Program Studi Matematika, Fakultas MIPA - Universitas Udayana [Email: nymdickywijaya@gmail.com] \\ ${ }^{2}$ Program Studi Matematika, Fakultas MIPA - Universitas Udayana [Email: gandhiadi@unud.ac.id] \\ ${ }^{3}$ Program Studi Matematika, Fakultas MIPA - Universitas Udayana [Email: ballidah@unud.ac.id] \\ ${ }^{\S}$ Corresponding Author
}

\begin{abstract}
Boarding house is an alternative choice for students to fulfill their need for a place to live. The variety of boarding houses, along with their respective advantages and disadvantages, becomes a challenge for students in determining the boarding house that suits their desires and needs. An in-depth evaluation is needed by comparing boarding houses based on certain criteria. In this study will be known the best boarding house based on four assessment criteria, price, facility, location, and room area. This research was conducted in Mathematics Department, Udayana University, using the combination of Fuzzy Analytic Hierarchy Process (FAHP) and Simple Additive Weighting (SAW) method. Sample in this study amounted to 118 respondents, with purposive sampling was the sampling technique. FAHP method is used to obtain the weight of each criterion, with the use of triangular fuzzy numbers for pairwise comparison scale of FAHP, and the use of the extent analysis method for the synthetic extent value $\left(S_{i}\right)$ of the pairwise comparison. SAW method is used for the ranking process of 75 boarding houses alternative. The result showed that the weight of each criterion being 32\% (price), 23\% (facility), $40 \%$ (location), and 5\% (room area), obtained A46 as the best boarding houses with a percentage gain value of $71 \%$.
\end{abstract}

Keywords: Boarding House, Fuzzy Analytic Hierarchy Process (FAHP), Simple Additive Weighting $(S A W)$

\section{PENDAHULUAN}

Indekos menurut Kamus Besar Bahasa Indonesia (KBBI) merupakan aktivitas tinggal di rumah orang lain dengan membayar setiap bulan, baik dengan ataupun tanpa makan. Indekos menjadi suatu upaya yang dilakukan manusia dalam memenuhi kebutuhannya akan tempat tinggal, mengingat tempat tinggal merupakan kebutuhan dasar manusia dalam melangsungkan kehidupannya (Widyosiswoyo, 1991).

Untuk memenuhi kebutuhan mahasiswa perantau akan tempat tinggal, dapat dilakukan dengan memanfaatkan fasilitas kampus berupa asrama atau rusunawa. Akan tetapi, dengan jumlah mahasiswa yang dapat ditampung terbatas, rumah indekos menjadi alternatif pilihan tempat tinggal sementara bagi mahasiswa.

Beragamnya alternatif indekos yang ada beserta kelebihan dan kekurangannya masing- masing, menjadi tantangan bagi mahasiswa dalam menentukan rumah indekos yang sesuai dengan keinginan serta kebutuhannya. Dibutuhkan evaluasi mendalam dengan membandingkan satu rumah indekos dengan rumah indekos lain berdasarkan kriteria tertentu. Adapun kriteria yang menjadi pertimbangan dalam memilih rumah indekos antara lain harga, fasilitas, lokasi, dan luas kamar. Pada penelitian yang dilakukan Tampubolon (2018), variabel harga, fasilitas dan lokasi, secara serempak memengaruhi keputusan mahasiswa dalam memilih rumah indekos. Sedangkan Fahlepi \& Widjaja (2019) menyatakan luas kamar memengaruhi harga sewa indekos, dimana semakin luas kamar indekos maka semakin tinggi harga yang ditawarkan pemilik indekos.

Berdasarkan permasalahan tersebut, dibutuhkan suatu penelitian untuk mengetahui bagaimana alternatif indekos terbaik diperoleh 
berdasarkan kriteria penilaian tertentu. Satu cara yang dapat digunakan yaitu dengan Fuzzy Multiple Attribute Decision Making (FMADM).

Multiple Attribute Decision Making (MADM) merupakan metode pengambilan keputusan yang melibatkan pemilihan diantara sejumlah alternatif, berdasarkan atribut penilaian yang ditetapkan (Hwang \& Yoon, 1981). Alternatif merupakan pilihan diantara dua atau lebih kemungkinan, dimana dari banyaknya alternatif yang ada, akan disaring, diprioritaskan, kemudian dipilih dan diberi peringkat. Atribut merupakan dasar pertimbangan yang digunakan dalam menilai alternatif (diasosiasikan sebagai kriteria).

Pada metode MADM dibutuhkan informasi mengenai tingkat kepentingan (bobot) masing-masing kriteria. Pada penelitian yang dilakukan oleh Saaty (1990), bobot tiap kriteria diperoleh melalui perbandingan penilaian antar kriteria dengan Analytic Hierarchy Proccess (AHP). Penilaian dilakukan dengan membandingkan dua buah kriteria, kemudian ditetapkan suatu nilai yang menunjukkan seberapa dominan kriteria tersebut atas kriteria lainnya, berdasarkan skala perbandingan Saaty (Tabel 1).

Tabel 1. Skala Perbandingan Saaty

\begin{tabular}{|c|c|}
\hline $\begin{array}{c}\text { Intensitas } \\
\text { Kepentingan }\end{array}$ & Definisi \\
\hline 1 & Sama penting \\
\hline 3 & Agak penting \\
\hline 5 & Lebih penting \\
\hline 7 & Sangat penting \\
\hline 9 & Mutlak penting \\
\hline $2,4,6,8$ & $\begin{array}{c}\text { Nilai antara dua penilaian yang } \\
\text { berdekatan }\end{array}$ \\
\hline
\end{tabular}

Sumber: Saaty (1990)

Perbandingan penilaian antar kriteria tersebut kemudian disusun ke dalam suatu matriks, diperoleh matriks perbandingan berpasangan, $C=\left(a_{i j}\right)_{n x n}$, pada Tabel 2 .

Tabel 2. Matriks Perbandingan Berpasangan $(C)$

\begin{tabular}{|c|c|c|c|c|c|}
\hline & $C_{1}$ & $C_{2}$ & $C_{3}$ & $\cdots$ & $C_{n}$ \\
\hline$C_{1}$ & $a_{11}$ & $a_{12}$ & $a_{13}$ & $\cdots$ & $a_{1 n}$ \\
\hline$C_{2}$ & $a_{21}$ & $a_{22}$ & $a_{23}$ & $\cdots$ & $a_{2 n}$ \\
\hline$C_{3}$ & $a_{31}$ & $a_{32}$ & $a_{33}$ & $\cdots$ & $a_{3 n}$ \\
\hline$\vdots$ & $\vdots$ & $\vdots$ & $\vdots$ & & $\vdots$ \\
\hline$C_{n}$ & $a_{n 1}$ & $a_{n 2}$ & $a_{n 3}$ & $\cdots$ & $a_{n n}$ \\
\hline
\end{tabular}

dengan $C_{i}(i, j=1,2,3, \ldots, n)$ himpunan $n$ kriteria dan $a_{i j}(i, j=1,2,3, \ldots, n)$ perbandingan penilaian kriteria ke- $i$ terhadap kriteria ke- $j$.

Input utama dalam metode AHP merupakan persepsi manusia, dimana terdapat faktor subjektifitas dalam pengambilan keputusan. Hal ini memungkinkan terjadinya ketidakkonsistenan pada data yang diperoleh, sehingga perlu dilakukan uji konsistensi terhadap penilaian tersebut. Batas ketidakkonsistenan matriks ditentukan berdasarkan rasio konsistensi $(C R)$ yakni $C R<$ 0,1 , melalui persamaan:

$$
C R=\frac{C I}{R I}
$$

Nilai $C I$ diperoleh melalui persamaan:

$$
C I=\frac{\left(\lambda_{\max }-n\right)}{(n-1)}
$$

dimana $\lambda_{\max }$ merupakan nilai eigen terbesar dari matriks berordo $n$, yang memenuhi persamaan $C x=\lambda_{\max } x$, diperoleh melalui hasil perkalian skalar jumlah masing-masing kolom matriks $(C)$ terhadap vektor eigen $\left(x_{i}\right)$ (Saaty, 1987), melalui persamaan:

$$
\lambda_{\max }=\sum_{j=1}^{n} \sum_{i=1}^{n} a_{i j} x_{i}
$$

dengan vektor eigen $x$ diperoleh dari hasil normalisasi nilai rata-rata geometrik masingmasing baris pada matriks perbandingan berpasangan (Saaty \& Kearns, 1985), melalui persamaan:

$$
x_{i}=\frac{\left(\prod_{j=1}^{n} a_{i j}\right)^{1 / n}}{\sum_{i=1}^{n}\left(\prod_{j=1}^{n} a_{i j}\right)^{1 / n}}
$$

Sedangkan nilai $R I$ (random index) bergantung pada ordo matriks $n$, diperlihatkan pada Tabel 3.

Tabel 3. Random Index

\begin{tabular}{|c|c|}
\hline $\boldsymbol{n}$ & $\boldsymbol{R I}$ \\
\hline 1 & 0,00 \\
\hline 2 & 0,00 \\
\hline 3 & 0,52 \\
\hline 4 & 0,89 \\
\hline 5 & 1,11 \\
\hline 6 & 1,25 \\
\hline 7 & 1,35 \\
\hline 8 & 1,40 \\
\hline 9 & 1,45 \\
\hline 10 & 1,49 \\
\hline
\end{tabular}

Sumber: Saaty \& Vargas (2012)

Tidak jarang informasi yang diperoleh tidak dapat dinilai secara tepat. Ketidaktepatan tersebut berasal dari berbagai sumber seperti informasi yang tidak dapat diukur, 
ketidaklengkapan informasi, informasi yang sulit diperoleh, sehingga penilaian subjektif oleh individu digunakan dalam memperoleh informasi tersebut (Chen \& Hwang, 1992). Untuk mengatasi permasalahan tersebut, teori himpunan fuzzy digunakan untuk menghindari ketidaklengkapan, ketidaktepatan, serta ketidakkonsistenan data yang diakibatkan oleh input utama berupa persepsi manusia, yang tidak dapat dilakukan dengan MADM biasa (Chen \& Hwang, 1992).

Pada penelitian yang dilakukan Chang (1996), fuzzy triangular number (FTN) digunakan dalam skala penilaian tingkat kepentingan antar kriteria pada metode Fuzzy Analytic Hierarchy Process (FAHP), ditunjukkan pada Tabel 4.

Tabel 4. Skala Perbandingan FTN

\begin{tabular}{|c|c|}
\hline Skala Saaty & Skala FTN \\
\hline 1 & $(1,1,1)$ \\
\hline 2 & $(1,2,3)$ \\
\hline 3 & $(2,3,4)$ \\
\hline 4 & $(3,4,5)$ \\
\hline 5 & $(4,5,6)$ \\
\hline 6 & $(5,6,7)$ \\
\hline 7 & $(6,7,8)$ \\
\hline 8 & $(7,8,9)$ \\
\hline 9 & $(8,9,9)$ \\
\hline
\end{tabular}

Sumber: Hsu et al. (2010)

dengan matriks perbandingan berpasangan antar kriteria yakni $C=\left(a_{i j}\right)_{n x n}$, dimana elemennya $a_{i j}=\left(l_{i j}, m_{i j}, u_{i j}\right)$, merupakan FTN.

Kemudian dengan metode analysis extent, nilai synthetic extent $S_{i}$ diperoleh dari matriks perbandingan berpasangan yang terbentuk, dan berdasarkan prinsip perbandingan bilangan fuzzy, diperoleh bobot dari masing-masing kriteria (Chang, 1996), melalui tahapan analisis sebagai berikut:

1) Konversi nilai dari skala Saaty ke dalam skala FTN pada matriks perbandingan berpasangan yang diperoleh, berdasarkan Tabel 4.

2) Agregasi pendapat dilakukan dengan mencari nilai rata-rata tiap elemen dari keseluruhan matriks yang diperoleh.

3) Menentukan nilai fuzzy synthetic extent $\left(S_{i}\right)$

$$
S_{i}=\sum_{j=1}^{m} M_{g_{i}}^{j} \odot\left[\sum_{i=1}^{n} \sum_{j=1}^{m} M_{g_{i}}^{j}\right]^{-1}
$$

$$
\sum_{j=1}^{m} M_{g_{i}}^{j}=\sum_{j=1}^{m} l_{j}, \sum_{j=1}^{m} m_{j}, \sum_{j=1}^{m} u_{j}
$$

4) Prinsip perbandingan bilangan fuzzy digunakan untuk mengestimasi nilai bobot tiap kriteria. Misalkan $S_{i}=\left(l_{i}, m_{i}, u_{i}\right)$

$$
\begin{aligned}
V(S & \left.\geq S_{1}, S_{2}, \ldots, S_{k}\right) \\
& =V\left[\left(S \geq S_{1}\right) \wedge \ldots \wedge\left(S \geq S_{k}\right)\right] \\
& =\min V\left(S \geq S_{i}\right), i=1,2, \ldots, k
\end{aligned}
$$

dengan

$$
\begin{aligned}
V & \left(S_{1} \geq S_{2}\right) \\
& =\left\{\begin{array}{c}
1, \text { jika } m_{1} \geq m_{2} \\
\frac{l_{1}-u_{2}}{\left(m_{2}-u_{2}\right)-\left(m_{1}-l_{1}\right)}, \text { lainnya }
\end{array}\right.
\end{aligned}
$$

Diasumsikan

$$
d^{\prime}\left(C_{i}\right)=\min V\left(S_{i} \geq S_{k}\right)
$$

dengan $k=1,2, \ldots, n ; k \neq i$. Vektor bobot masing-masing kriteria diberikan sebagai berikut:

$$
w^{\prime}=\left(d^{\prime}\left(C_{1}\right), d^{\prime}\left(C_{2}\right), \ldots, d^{\prime}\left(C_{n}\right)\right)^{T}
$$

5) Melalui proses normalisasi, diperoleh vektor bobot ternormalisasi sebagai berikut:

$$
w=\left(d\left(C_{1}\right), d\left(C_{2}\right), \ldots, d\left(C_{n}\right)\right)^{T}
$$

Guna menentukan alternatif mana yang kemudian dipilih sebagai alternatif terbaik, dibutuhkan proses perankingan alternatif berdasarkan bobot tiap kriteria. Simple Additive Weighting (SAW) merupakan suatu metode yang dapat digunakan untuk mengevalusai alternatif yang dilakukan melalui penjumlahan hasil perkalian rating kinerja matriks keputusan ternormalisasi dengan bobot tiap kriteria pada setiap alternatif $V_{i}(i=1,2,3, \ldots, n)$, melalui persamaan:

$$
V_{i}=\sum_{i=1}^{n} r_{i j} w_{j}
$$

Matriks keputusan adalah matriks yang elemennya merepresentasikan perbandingan antar $m$ alternatif $A_{i}(i=1,2,3, \ldots, m)$ terhadap $n$ kriteria $C_{j}(j=1,2,3, \ldots, n)$, ditunjukkan pada Tabel 5.

Tabel 5. Matriks Keputusan

\begin{tabular}{|c|c|c|c|c|c|}
\hline & $C_{1}$ & $C_{2}$ & $C_{3}$ & $\cdots$ & $C_{n}$ \\
\hline$A_{1}$ & $x_{11}$ & $x_{12}$ & $x_{13}$ & $\cdots$ & $x_{1 n}$ \\
\hline$A_{2}$ & $x_{21}$ & $x_{22}$ & $x_{23}$ & $\cdots$ & $x_{2 n}$ \\
\hline$A_{3}$ & $x_{31}$ & $x_{32}$ & $x_{33}$ & $\cdots$ & $x_{3 n}$ \\
\hline$\vdots$ & $\vdots$ & $\vdots$ & $\vdots$ & & $\vdots$ \\
\hline$A_{n}$ & $x_{m 1}$ & $x_{m 2}$ & $x_{m 3}$ & $\cdots$ & $x_{m n}$ \\
\hline
\end{tabular}

dengan $x_{i j}$ merupakan rating kinerja alternatif ke- $i$ terhadap kriteria ke- $j$. Normalisasi matriks keputusan didasari pada persamaan yang disesuaikan dengan jenis kriteria. Terdapat dua 
jenis kriteria yakni kriteria cost dan kriteria benefit. Mudahnya kriteria cost apabila semakin tinggi nilainya akan semakin merugikan pengambil keputusan, sedangkan kriteria benefit sebaliknya. Normalisasi matriks keputusan dilakukan melalui persamaan berikut:

$$
r_{i j}=\left\{\begin{array}{l}
\frac{x_{i j}}{\operatorname{Max} x_{i j}} ; j i k a j=\text { kriteria benefit } \\
\frac{\operatorname{Min} x_{i j}}{x_{i j}} ; j i k a j=\text { kriteria cost }
\end{array}\right.
$$

dengan $r_{i j}$ merupakan rating kinerja matriks keputusan ternormalisasi, $\operatorname{Max} x_{i j}$ nilai $x_{i j}$ terbesar, dan $\operatorname{Min} x_{i j}$ nilai $x_{i j}$ terkecil.

Pada penelitian Julianto (2020) FAHP dan SAW diimplementasikan pada evaluasi kualitas mengajar dosen. Melalui enam kriteria penilaian yakni isi, metode, dan efek pembelajaran, kemampuan dosen mengajar, sikap mengajar, dan target pengajar, dengan bobot masing-masing kriteria berturut-turut 0,164, 0,231, 0,274, 0,198, 0,109, dan 0,024. Diperoleh Dosen 6 sebagai dosen dengan kualitas mengajar terbaik. Afshari et al. (2017) dalam penelitiannya tentang perekrutan karyawan perusahaan telekomunikasi. Dari 40 kandidat yang mengikuti ujian tulis, diperoleh Kandidat 3 sebagai karyawan terpilih berdasarkan tujuh kriteria penilaian menggunakan FAHP dan SAW.

Penelitian ini bertujuan untuk mengetahui alternatif indekos terbaik berdasarkan empat kriteria penilaian yakni harga, fasilitas, lokasi, dan luas kamar dengan kombinasi metode FAHP guna memperoleh bobot masing-masing kriteria dan metode SAW saat proses perangkingan alternatif.

\section{METODE PENELITIAN}

\subsection{Jenis dan Sumber Data}

Data pada penelitian ini adalah data primer yang diperoleh dengan metode survei melalui penyebaran kuesioner. Data bersumber dari responden penelitian yaitu mahasiswa aktif Program Studi Matematika, Universitas Udayana.

\subsection{Teknik Pengambilan Sampel}

Populasi yang dilibatkan dalam penelitian ini merupakan mahasiswa aktif Program Studi Matematika, Universitas Udayana. Pengambilan sampel melalui teknik purposive sampling dilakukan dengan kriteria sampel yakni responden merupakan mahasiswa aktif
Program Studi Matematika, Universitas Udayana, yang memiliki pengalaman tinggal di rumah indekos. Diperoleh sampel sejumlah 118 mahasiswa, 42 mahasiswa angkatan 2017, 27 mahasiswa angkatan 2018, dan 49 mahasiswa angkatan 2019.

\subsection{Variabel Penelitian}

Terdapat empat variabel dalam penelitian ini, yaitu:

1) Harga (C1)

Harga merupakan sejumlah uang yang harus dibayarkan atas suatu produk atau jasa (Kotler \& Armstrong, 2008).

2) Fasilitas (C2)

Fasilitas merupakan segala sesuatu yang dapat mempermudah dan memperlancar usaha yang dibutuhkan guna mencapai suatu tujuan (Daradjat, 2002).

3) Lokasi (C3)

Lokasi merupakan letak atau tempat beradanya sesuatu (KBBI).

4) Luas Kamar (C4)

Luas kamar merupakan besar area atau wilayah kamar yang umumnya disekat atau dibatasi empat dinding, dengan satuan meter persegi (KBBI).

Variabel dalam penelitian ini terangkum dalam enam pertanyaan dengan jawaban responden diukur pada skala interval 1-9. Saat mengisi kuesioner, responden diwajibkan memilih satu dari dua variabel yang dibandingkan, kemudian menetapkan tingkat dominasi variabel yang dipilih pada skala interval 1-9.

\subsection{Teknik Analisis Data}

Adapun analisis data dilakukan melalui tahapan berikut:

1) Melakukan uji konsistensi jawaban responden, berupa data perbandingan penilaian antar kriteria, guna mengetahui konsistensi penilaian responden. Apabila penilaian responden terbukti tidak konsisten, maka dilakukan penilaian ulang hingga penilaian tersebut dinyatakan konsisten dengan nilai rasio konsistensi kurang dari $0,1(C R<0,1)$.

2) Pembobotan tiap kriteria dengan metode FAHP melalui tahapan berikut:

(1) Melakukan konvesi nilai dari skala Saaty ke dalam skala fuzzy pada 118 matriks perbandingan berpasangan yang diperoleh, berdasarkan Tabel 4 . 
(2) Agregasi pendapat 118 responden, dilakukan dengan mencari nilai ratarata tiap elemen pada 118 matriks yang diperoleh.

(3) Bobot tiap kriteria kemudian diperoleh dengan prinsip pebandingan bilangan fuzzy

3) Alternatif indekos terbaik diperoleh dari perangkingan hasil perkalian matriks keputusan ternormalisasi $(R)$ terhadap vektor bobot $(w)$ dengan metode SAW, melalui tahapan berikut:

(1) Menyusun matriks keputusan setiap alternatif terhadap kriteria

(2) Normalisasi matriks keputusan berdasarkan jenis atribut

(3) Perkalian matriks keputusan ternormalisasi $(R)$ terhadap vektor bobot $(w)$, alternatif dengan nilai tertinggi terpilih sebagai alternatif indekos terbaik.

4) Interpretasi Hasil.

\section{HASIL DAN PEMBAHASAN}

\subsection{Gambaran Umum Data}

Sebanyak 118 kuesioner disebarkan kepada mahasiswa aktif Program Studi Matematika, Universitas Udayana. Karakteristik responden yang dipertimbangkan adalah tahun angkatan dan jenis kelamin. Ditinjau dari tahun angkatan, responden dalam penelitian ini didominasi mahasiswa angkatan 2019 berjumlah 49 responden, 42 responden dari angkatan 2017, dan 27 responden dari angkatan 2018. Sedangkan apabila ditinjau dari jenis kelamin, penelitian ini didominasi responden wanita berjumlah 81 responden, dan 37 responden laki-laki.

Dari hasil survei melalui kuesioner, diperoleh data berupa perbandingan penilaian antar kriteria dengan skala penilaian 1-9. Data ini digunakan untuk mengetahui bobot tiap kriteria yang akan digunakan dalam proses pemilihan alternatif. Alternatif dalam penelitian ini merupakan rumah indekos yang berada di lingkungan Program Studi Matematika, Universitas Udayana. Berdasarkan hasil survei, diperoleh data 118 indekos berupa data harga sewa indekos per bulan, fasilitas yang disediakan pemilik indekos, lokasi serta luas kamar indekos. Setelah dilakukan cleaning data dikarenakan terdapat data ganda, yang diakibatkan karena terdapat indekos yang dihuni lebih dari satu responden, diperoleh 75 alternatif indekos yang akan dibandingkan dalam penelitian ini.

\subsection{Uji Konsistensi Penilaian Responden}

Langkah awal dalam penelitian ini yakni uji konsistensi jawaban responden atas sejumlah pertanyaan dalam kuesioner. Responden diwajibkan untuk memilih satu dari dua kriteria yang dibandingkan, melalui pertanyaan "Menurut saudara/i, manakah diantara kriteria berikut yang lebih dominan memengaruhi keputusan Anda dalam memilih rumah indekos?". Kemudian ditetapkan suatu nilai yang menunjukkan tingkat dominasi kriteria tersebut berdasarkan skala pada Tabel 1.

Perbandingan penilaian responden pertama (R1) apabila disusun ke dalam suatu matriks, direpresentasikan pada Tabel 6.

Tabel 6. Matriks Perbandingan Berpasangan R1

\begin{tabular}{|c|c|c|c|c|c|}
\hline & $\mathrm{C} 1$ & $\mathrm{C} 2$ & $\mathrm{C} 3$ & $\mathrm{C} 4$ & $x_{i}$ \\
\hline $\mathrm{C} 1$ & 1 & 5 & 2 & 5 & 0,48 \\
\hline $\mathrm{C} 2$ & $1 / 5$ & 1 & $1 / 4$ & 3 & 0,11 \\
\hline $\mathrm{C} 3$ & $1 / 2$ & 4 & 1 & 7 & 0,35 \\
\hline $\mathrm{C} 4$ & $1 / 5$ & $1 / 3$ & $1 / 7$ & 1 & 0,06 \\
\hline \multicolumn{5}{|c|}{$\lambda_{\max }=4,17, C I=0,056, C R=0,06$} \\
\hline
\end{tabular}

Data pada Tabel 6 menunjukkan kriteria harga lebih dominan dibandingkan kriteria fasilitas, dan kriteria fasilitas lebih dominan dibandingkan kriteria luas kamar. Penilaian Responden 1 dapat dinyatakan konsisten apabila kriteria harga juga lebih dominan dibandingkan kriteria luas kamar. Berdasarkan data pada Tabel 6, memang benar bahwa kriteria harga lebih dominan dibandingkan kriteria luas kamar, sehingga pendapat R1 tersebut dapat dinyatakan konsisten, dengan nilai $C R=0,06$.

Berdasarkan uji konsistensi diketahui bahwa 118 perbandingan penilaian oleh responden dinyatakan konsisten $(C R<0,1)$.

\subsection{Pembobotan Kriteria}

Tabel 7. Matriks Perbandingan Berpasangan R1 Skala FTN

\begin{tabular}{|l|cccc|}
\hline & C1 & C2 & C3 & C4 \\
\hline C1 & $(1,1,1)$ & $(4,5,6)$ & $(1,2,3)$ & $(4,5,6)$ \\
C2 & $(1 / 6,1 / 5,1 / 4)$ & $(1,1,1)$ & $(1 / 5,1 / 4,1 / 3)$ & $(2,3,4)$ \\
C3 & $(1 / 3,1 / 2,1)$ & $(3,4,5)$ & $(1,1,1)$ & $(6,7,8)$ \\
C4 & $(1 / 6,1 / 5,1 / 4)$ & $(1 / 4,1 / 3,1 / 2)$ & $(1 / 8,1 / 7,1 / 6)$ & $(1,1,1)$ \\
\hline
\end{tabular}


Langkah berikutnya yakni mengonversi matriks perbandingan berpasangan dengan skala Saaty ke skala FTN yang didefinisikan pada Tabel 4.
Matriks perbandingan berpasangan R1 dalam skala FTN direpresentasikan pada Tabel 7.

Tabel 8. Agregasi Matriks Perbandingan Berpasangan 118 Responden

\begin{tabular}{|c|cccc|}
\hline & $\mathrm{C} 1$ & $\mathrm{C} 2$ & $\mathrm{C} 3$ & $\mathrm{C} 4$ \\
\hline $\mathrm{C} 1$ & $(1,1,1)$ & $(2,19,2,77,3,39)$ & $(1,63,2,07,2,55)$ & $(2,93,3,66,4,39)$ \\
$\mathrm{C} 2$ & $(1,59,1,99,2,43)$ & $(1,1,1)$ & $(1,51,1,92,2,36)$ & $(2,55,3,20,3,88)$ \\
$\mathrm{C} 3$ & $(2,24,2,81,3,40)$ & $(2,65,3,25,3,87)$ & $(1,1,1)$ & $(3,28,4,02,4,80)$ \\
$\mathrm{C} 4$ & $(1,26,1,56,1,89)$ & $(1,36,1,75,2,19)$ & $(1,23,1,57,1,89)$ & $(1,1,1)$ \\
\hline
\end{tabular}

Kemudian dari agregasi pendapat 118 responden, diperoleh matriks agregasi perbandingan berpasangan 118 responden, ditunjukkan Tabel 8.

Dari matriks perbandingan berpasangan tersebut, nilai fuzzy synthetic extent dari masing-masing kriteria diperoleh melalui persamaan (5), sebagai berikut:

$S_{1}=(0,19,0,27,0,40)$

$S_{2}=(0,16,0,23,0,34)$

$S_{3}=(0,22,0,32,0,46)$

$S_{4}=(0,12,0,17,0,25)$

Berdasarkan persamaan (6) dan (7), diperoleh:

$V\left(S_{1} \geq S_{2}\right)=1$

$V\left(S_{1} \geq S_{3}\right)=\frac{0,22-0,40}{(0,27-0,40)-(0,32-0,22)}=0,79$

$V\left(S_{1} \geq S_{4}\right)=1$

$V\left(S_{2} \geq S_{1}\right)=\frac{0,19-0,34}{(0,23-0,34)-(0,27-0,19)}=0,79$

$V\left(S_{2} \geq S_{3}\right)=\frac{0,22-0,34}{(0,23-0,34)-(0,32-0,22)}=0,58$

$V\left(S_{2} \geq S_{4}\right)=1$

$V\left(S_{3} \geq S_{1}\right)=1$

$V\left(S_{3} \geq S_{2}\right)=1$

$V\left(S_{3} \geq S_{3}\right)=1$

$V\left(S_{4} \geq S_{1}\right)=\frac{0,19-0,25}{(0,17-0,25)-(0,27-0,19)}=0,35$

$V\left(S_{4} \geq S_{2}\right)=\frac{0,16-0,25}{(0,17-0,25)-(0,23-0,16)}=0,56$

$V\left(S_{4} \geq S_{3}\right)=\frac{0,22-0,25}{(0,17-0,25)-(0,32-0,22)}=0,13$

Kemudian untuk mengestimasi nilai bobot dari masing-masing kriteria, digunakan prinsip perbandingan bilangan fuzzy, berdasarkan persamaan (8), diperoleh nilai sebagai berikut:

$d^{\prime}\left(C_{1}\right)=\min V\left(S_{1} \geq S_{2}, S_{3}, S_{4}\right)=0,79$

$d^{\prime}\left(C_{2}\right)=\min V\left(S_{2} \geq S_{1}, S_{3}, S_{4}\right)=0,58$

$d^{\prime}\left(C_{3}\right)=\min V\left(S_{3} \geq S_{1}, S_{2}, S_{4}\right)=1$

$d^{\prime}\left(C_{4}\right)=\min V\left(S_{4} \geq S_{1}, S_{2}, S_{3}\right)=0,13$

Melalui proses normalisasi, diperoleh vektor bobot ternormalisasi sebagai berikut:

$$
w=(0,32,0,23,0,40,0,05)^{T}
$$

\subsection{Perangkingan Alternatif}

Kemudian dalam menentukan alternatif indekos terbaik dengan metode SAW, dilakukan melalui penjumlahan hasil perkalian matriks keputusan ternormalisasi $(R)$ terhadap vektor bobot $(w)$. Normalisasi matriks keputusan dilakukan berdasarkan persamaan (5), dengan jenis kriteria ditunjukkan Tabel 9.

Tabel 9. Jenis Kriteria

\begin{tabular}{|c|c|}
\hline Kriteria & Jenis Kriteria \\
\hline C1 & Cost \\
C2 & Benefit \\
C3 & Cost \\
C4 & Benefit \\
\hline
\end{tabular}

Dari 75 alternatif indekos yang dibandingkan, diperoleh lima posisi indekos teratas, ditunjukkan Tabel 10.

Tabel 10. Perangkingan menggunakan SAW

\begin{tabular}{|c|c|c|}
\hline Alternatif & $\sum r_{i j} w_{j}$ & Rangking \\
\hline A46 & 0,71 & 1 \\
\hline A18 & 0,67 & 2 \\
\hline A12 & 0,55 & 3 \\
\hline A20 & 0,54 & 4 \\
\hline A31 & 0,53 & 5 \\
\hline
\end{tabular}

\section{KESIMPULAN}

Persoalan utama dalam metode MADM adalah pemilihan alternatif yang tepat dari sejumlah alternatif yang ada, berdasarkan kriteria tertentu. Penelitian ini bertujuan untuk memilih indekos terbaik di lingkungan Program Studi Matematika, Universitas Udayana berdasarkan kriteria harga, fasilitas, lokasi, dan luas kamar. Berdasarkan perhitungan melalui metode FAHP diperoleh bobot tiap kriteria, disajikan pada Tabel 11. 
Tabel 11. Bobot Kriteria

\begin{tabular}{|c|c|}
\hline Kriteria & Persentase (\%) \\
\hline Harga (C1) & 32 \\
\hline Fasilitas (C2) & 23 \\
\hline Lokasi (C3) & 40 \\
\hline Luas Kamar (C4) & 5 \\
\hline
\end{tabular}

Akan mudah menentukan indekos terbaik apabila terdapat alternatif yang memenuhi keempat kriteria tersebut, yakni apabila memiliki harga sewa termurah, dengan fasilitas terlengkap, berlokasi paling dekat dengan kampus, dan memiliki luas kamar terbesar. Akan tetapi, berdasarkan data alternatif indekos yang diperoleh tidak terdapat satupun indekos yang memenuhi hal tersebut.

Berbekal informasi mengenai bobot tiap kriteria, alternatif terbaik diperoleh berdasarkan perhitungan melalui metode SAW terhadap 75 alternatif indekos, diperoleh A46 sebagai alternatif indekos terbaik.

\section{DAFTAR PUSTAKA}

Afshari, A. R., Nikolic, M., \& Zahra, A. 2017. "Personnel Selection Using Group Fuzzy AHP and SAW Methods". Journal of Engineering Management and Competitiveness, 7(1), 3-10.

Chang, D. Y. 1996. "Applications of the extent analysis method on fuzzy AHP". European Journal of Operational Research, 95, 649655.

Chen, S.-J., \& Hwang, C.-L. 1992. Fuzzy Multiple Attribute Decision Making Methods and Applications. Berlin: SpringerVerlag.

Christioko, B. V., Indriyawati, H., \& Hidayati, N. 2017. "Fuzzy Multi-Attribute Decision Making (Fuzzy MADM) Dengan Metode SAW Untuk Pemilihan Mahasiswa Berprestasi”. Jurnal Transformatika, 14(2), 82-85.

Fahlepi, M. R., \& Widjaja, A. 2019. "Penerapan Metode Multiple Linear Regression Untuk Prediksi Harga Sewa Kamar Kost", Jurnal Strategi, 1(2), 615629.

Hsu, Y. L., Lee, C. H., \& Kreng, V. B. 2010. "The application of Fuzzy Delphi Method and Fuzzy AHP in lubricant regenerative technology selection". Expert Systems with
Applications, 37, 419-425.

Hwang, C.-L., \& Yoon, K. 1981. Multiple Attribute Decision Making Methods and Applications. Berlin: Springer-Verlag.

Julianto, V. 2020. “Analisis Sistem Pendukung Keputusan Evaluasi Kualitas Mengajar Dosen Menggunakan Metode Fuzzy AHP dan SAW". Jurnal Sains dan Informatika, $6(1), 10-19$.

Kusumadewi, S., Hartati, S., Harjoko, A., \& Wardoyo, R. 2006. Fuzzy Multi-Attribute Decision Making (FMADM). Yogyakarta: Graha Ilmu.

Saaty, R. W. 1987. "The Analytic Hierarchy Process - What It Is and How It Is Used". Math Modelling, 9(3-5), 161-176.

Saaty, T. L. 1990. "How to make a decision: The Analytic Hierarchy Process". European Journal of Operational Research, 48, 9-26.

Saaty, T. L., \& Kearns, K. P. 1985. Analytical Planning The Organization of Systems (Vol. 7). USA: Pergamon Press.

Saaty, T. L., \& Vargas, L. G. 2012. Models, Methods, Concepts \& Applications of The Analytic Hierarchy Process. USA: Springer.

Tampubolon, V. 2018. "Pengaruh Lokasi, Harga dan Fasilitas Terhadap Keputusan dalam Memilih Jasa Rumah Kos pada Mahasiswa Universitas Sumatera Utara". Skripsi. Universitas Sumatera Utara. Medan.

Widyosiswoyo, H. S. 1991. Ilmu Alamiah Dasar. Jakarta Timur: Ghalia Indonesia. 